\title{
Ficolin-2 a newmarker for severity of liver inflammation in patients with chronic hepatitis $\mathbf{C}$ \\ Abd El Monem M. Barrak*, Hesham E. Lashin*, Mahmoud M. Metwally** and Nabil I. Abd El-Rahman* \\ Internal Medicine* and Clinical Pathology**Departments, Faculty of Medicine, Al-Azhar University (Cairo)
}

Corresponding author: Nabil I. Abd El-Rahman, Email: ahmed1hussein91@gmail.com

\begin{abstract}
Background: ficolin-2 is a kind of human serum complement lectin with a structure similar to mannan-binding lectin (MBL) and it has been implicated in innate immunity. Recent studies have shown that complement pathway activation may contribute to hepatitis. However, the relationship between ficolin-2 and viral hepatitis remains largely elusive. Aim of the work: This study aimed to determine the dynamics of ficolin-2 in patients with chronic hepatitis C. Patients and Methods: Thirty patients who had not yet received therapy and twenty normal control subjects were included in this study. A sandwich enzyme-linked immunosorbent assay (ELISA) was used to measure the ficolin-2 concentrations in all serum samples of patients and 20 healthy donors. Results: We found that the concentrations of ficolin-2 were significantly higher in chronic hepatitis $\mathrm{C}$ patients with abnormal ALT values than in chronic hepatitis C patients with normal ALT values and healthy controls. Ficolin-2 concentrations in chronic hepatitis C patients with abnormal ALT values were positively correlated with ALT levels $(* \mathrm{P}<0.05)$. Then, we found ficolin-2 concentrations in rapid viral response (RVR) group decreased significantly (*P $<0.05)$, while in non-RVR group, ficolin-2 decreased slightly $(\mathrm{P}>0.05)$. Conclusion: Our findings suggested that early increased ficolin-2 is highly correlated with hepatic inflammation and rapid viral response.
\end{abstract}

Keywords: ficolin-2, Liver inflammation, Chronic H CV.

\section{INTRODUCTION}

Hepatitis $\mathbf{C}$ virus (HCV)infects 170 million people worldwide and approximately $80 \%$ of infected individuals developed chronic hepatitis with a risk of progression to cirrhosis and hepatocellular carcinoma ${ }^{[1]}$.Humoral innate immune proteins that play a role in antiinfection include pentraxins and defense collagens such as C-type lectins and ficolins ${ }^{[2]}$.Ficolin-2 (which has a molecular weight of $35 \mathrm{kDa}$ of a single chain) was first cloned and described as a type of lectin (carbohydrate-binding proteins) with a structure and function similar to C1q, MBL and lung surfactant proteins A and D (SP-A and SP-D $)^{[3]}$. Both MBLand ficolin-2 are produced mainly by the liver and M-ficolin is produced by cells in the bone marrow and cells derived from the bone marrow. They are able to recognize conserved pathogen associated molecular patterns on the surface of invading pathogens and initiate the innate immune response ${ }^{[4]}$.

Humans have three types of ficolins; they are present in the bloodstream: M-ficolin (monocyte ficolin or ficolin-1); L-ficolin (liver ficolin or ficolin-2) andH-ficolin (Hakata antigen or ficolin-3).M- andL-ficolin have approximately $80 \%$ identity in amino acid sequence; $\mathrm{H}$-ficolin has only about 50\% identity with the other two ${ }^{[5]}$.M-ficolin, predominantly found in monocytes and granulocytes, is the homologue of murine ficolin-Band porcine ficolin- $\beta$; L-ficolin is the homologue of murine ficolin-A and porcine ficolin- $\alpha^{[5]}$.The third human ficolin, the Hakata antigen originally identified and defined by autoantibodies present in a small minority of lupus patients, is synthesized in both liver (secreted into bile as well as blood) and lung (and secretedinto the bronchi). It is the most abundant plasma ficolin and the most potent at activating complement in vitro ${ }^{[6]}$.All the three have the ability to activate the lectin pathway of complement, an activity known to be shared with just two collectins, mannan-binding lectin(MBL) and CL-L1 ${ }^{[7,8]}$.L-ficolin (like MBL) appeared to be a major pattern recognition molecule in human plasma ${ }^{[9]}$.It has a uniquely complex set of binding sites, potentially conferring the ability to recognize and interact with a wide range of pathogen ${ }^{[10]}$. Recently, it was found that ficolin-2 had specificity for the HCV envelope glycoproteins E1 and E2, resulting in 
activation of the complement cascade in vitro. However,still there is much debate about its relation to the degree of liver inflammation. The aim of the work is to evaluate the relationship between ficolin-2 and degree of liver affection in chronic hepatitis Cvirus infection.

\section{PATIENTS and METHODS}

The present study was carried out on50 subjects and classified into two groups; thirty patients with chronic hepatitis $\mathrm{C}$ infection (patients group I) 18 males and 12 females; their mean age was $(44.33 \pm 8.99)$ years and twenty healthy subjects (control group II) 12 males and 8 females; their mean age was (38.25 \pm 5.64$) y e a r s . T h e y$ were selected from the outpatient clinic and admitted to Internal Medicine Department of Sayed Galal Hospital, Al-Azhar University in the period betweenNovember 2017 and October 2018.This study was approved by hospital ethics committee and written consents were obtained from all patients after explaining the nature and the aim of the study. Patients with decompensate chronic liver disease, Patients with HCC, HBV, HDV orautoimmune hepatitis, Patients with malignancy or with active infection, andpreviously treated patients for HCVwere excluded from this study.All participated patients were subjected to the followings:

1-Full history taking with special emphasis on age, hepato-biliary symptomsand any symptoms suggest decompensated chronic liver diseaseandDuration of HCVinfection.

2-Clinical examination: complete physical examination with special emphasis on general examination including Cardiovascular,chest, abdominal and neurological examination to evaluate other systems.

3-Laboratory investigations including: $\mathrm{CBC}$, fasting plasma glucose (FPG), ALT, AST, s. bilirubin, s. ALB, ALP, INR, s. creatinine, total cholesterol(TC), triglycerides (TG), LDL$\mathrm{C}$ and HDL-C,HCV-Ab and HBVs-Ag by ELISA, HCV-RNA PCR, ANA, anti-liver kidney antibody.

4- Abdominal UIS, assessment of degree of liver inflammation and fibrosis by fibroscan.

5- Measurement of serum ficolin-2 concentrations by Enzyme-linked immunosorbent assay (ELISA) method ${ }^{[3,11]}$.
Statistical analysis: data were fed to the computer and analyzed using IBM SPSS (Statistical Package for the Social Science) software package version 20 as follows: qualitative data were described using number and percent, quantitative data were described using range (minimum and maximum), mean \pm standard deviation (SD) and median. Comparison between different groups regarding categorical variables was tested using Chi-square test. The distributions of quantitative variables were tested for normality using Kolmogorov-Smirnov test, Shapiro-Wilk test and D'Agstino test, also Histogram and QQ plot were used for vision test. If it reveals normal data distribution, parametric tests were applied. If the data were abnormally distributed, non-parametric tests were used:

For normally distributed data, comparison between 2 independent populations were done using independent $t$-test while $>2$ populations were analyzed using F-test (ANOVA) and Post Hoc test (Scheffe), Correlations between 2 quantitative variables were assessed using Pearson coefficient (r).

$\square$ For abnormally distributed data, comparison between 2 independent populations were done using Mann Whitney test while Kruskal Wallis test was used to compare between different groups. Significance test results are quoted as 2-tailed probabilities. Significance of the obtained results was judged at the 5\% level.

All results were considered insignificant: if Pvalue $>0.05$, significant: if $P$ - value $\leq 0.05$, and highly significant: if $\mathrm{P}$-value $\leq 0.001$.

\section{RESULTS}

Fifty subjects were selected and classified into two groups; thirty patients with chronic hepatitis C infection (patients group I) 18 males and 12 females; their mean age was $(44.33 \pm 8.99)$ years and twenty healthy subjects (control group II) 12 males and 8 females; their mean age was $(38.25 \pm 5.64)$ years.

In the current study the obtained results showed that the mean serum of FCN2 in patient group was $154.39 \pm 48.0$ and in control group it was $66.58 \pm 8.37$. From these results it is noted that FCN2is significantly increased in both sexes (male and females) of patients group with chronicHCV compared with control group $(\mathrm{P}<0.05$, table 1). More specifically, this study revealed that 
FCN2ispositively correlates with elevated ALT values in patients with chronic hepatitis $\mathrm{C}(\mathrm{p}<0.05$ table 2$)$.

There wassignificant positive correlation between FCN2 levels and PCR-HCV, FibroScan and U/S changes in cases group $(\mathrm{R}=$ $0.46, \mathrm{P}<0.05$ table 2 ).

There was significant positive correlation between serum FCN2 levels and T. Bilirubin,
INRand ALP changes in patients group, and there is significant negative correlation between FCN2 levels and ALBchanges in patients group (table 3 ).

There was also significant negative correlation between FCN2 levels and Plat changes in patients group (Table 4).

Table 1: comparison betweenconcentrations (Mean SD) of FCN2, ALT, AST and HCV in the studied groups

\begin{tabular}{|c|c|c|c|c|}
\hline \multirow{2}{*}{ Parameters } & \multirow{2}{*}{ Groups $S$} & Males & Females & Total \\
\hline & & Mean SD & Mean SD & Mean SD \\
\hline \multirow{4}{*}{ FCN2(pig/mL) } & Control & $66.58 \pm 8.37$ & $56.75 \pm 12.16$ & $62.65 \pm 10.93$ \\
\hline & Cases & $154.39 \pm 48.0$ & $188.08 \pm 39.7$ & $167.87 \pm 47.28$ \\
\hline & F-value & 38.84 & 80.81 & 95.03 \\
\hline & p-value & 0.0000 & 0.0000 & 0.0000 \\
\hline \multirow{4}{*}{ ALT (U/L) } & Control & $26.67 \pm 5.63$ & $26.38 \pm 6.23$ & $26.55 \pm 5.72$ \\
\hline & Cases & $47.00 \pm 18.17$ & $59.25 \pm 17.49$ & $51.90 \pm 18.62$ \\
\hline & F-value & 13.99 & 25.67 & 34.67 \\
\hline & p-value & 0.0008 & 0.0001 & 0.0000 \\
\hline \multirow{4}{*}{$\operatorname{AST}(\mathrm{U} / \mathrm{L})$} & Control & $22.67 \pm 7.67$ & $28.88 \pm 10.01$ & $25.15 \pm 8.98$ \\
\hline & Cases & $35.67 \pm 8.01$ & $37.08 \pm 10.22$ & $36.23 \pm 8.82$ \\
\hline & F-value & 19.60 & 3.15 & 18.68 \\
\hline & p-value & 0.0001 & 0.0930 & 0.0001 \\
\hline \multirow{3}{*}{$\begin{array}{l}\mathrm{HCV} \\
(+\mathrm{Ve} \text { or }-\mathrm{Ve})\end{array}$} & Control & Negative & Negative & Negative \\
\hline & \multirow{2}{*}{ Cases } & 3603444 & 6082833 & 4595200 \\
\hline & & \pm 3398813 & \pm 3329441 & \pm 3535928 \\
\hline
\end{tabular}

Table 2: correlation between FCN2 and ALT, AST, Fibro-Scan and PCR-HCV in the studied groups

\begin{tabular}{|c|c|c|c|}
\hline \multirow{2}{*}{ Parameters \& Correlation } & \multicolumn{2}{|c|}{ FCN2 } \\
\cline { 2 - 4 } & Pearson Correlation & $0.959^{*}$ & -0.27 \\
\cline { 2 - 4 } ALT & Sig. (2-tailed) & 0.000 & 0.25 \\
\hline \multirow{2}{*}{ AST } & Pearson Correlation & 0.285 & 0.08 \\
\cline { 2 - 4 } & Sig. (2-tailed) & 0.127 & 0.75 \\
\hline \multirow{2}{*}{ PCR-HCV } & Pearson Correlation & $0.976^{*}$ & -- \\
\cline { 2 - 4 } & Sig. (2-tailed) & 0.000 & -- \\
\hline \multirow{2}{*}{ Fibro-Scan } & Pearson Correlation & $0.918^{*}$ & -- \\
\cline { 2 - 4 } & Sig. (2-tailed) & 0.000 & -- \\
\hline \multirow{2}{*}{ U/S } & Pearson Correlation & $0.959^{*}$ & -- \\
\cline { 2 - 4 } & Sig. (2-tailed) & 0.000 & -- \\
\hline
\end{tabular}

Table 3: correlation between FCN2 and of Alb, Creat, T Bil, INR and Alp in the studied groups

\begin{tabular}{|c|c|c|c|}
\hline \multicolumn{2}{|c|}{} & \multicolumn{2}{|c|}{ FCN2 } \\
\cline { 3 - 4 } \multicolumn{2}{|c|}{} & Patint & Control \\
\hline \multirow{2}{*}{ ALB } & Pearson Correlation & $-0.542^{*}$ & -0.20 \\
\cline { 2 - 4 } & Sig. (2-tailed) & 0.002 & 0.40 \\
\hline \multirow{2}{*}{ IN Bil } & Pearson Correlation & $0.686^{*}$ & 0.05 \\
\cline { 2 - 4 } & Sig. (2-tailed) & 0.000 & 0.83 \\
\cline { 2 - 4 } & Pearson Correlation & $0.412^{*}$ & -0.14 \\
\cline { 2 - 4 } & Sig. (2-tailed) & 0.024 & 0.55 \\
\cline { 2 - 4 } ALp & Pearson Correlation & 0.326 & $-0.505^{*}$ \\
\cline { 2 - 4 } & Sig. (2-tailed) & 0.04 & 0.02 \\
\hline
\end{tabular}


Ficolin-2 a newmarker for severity of liver inflammation in patients with chronic hepatitis $\mathrm{C}$

Table 4: correlation between FCN2 and Plat, Hb, WBC Chol, T G, LDL-c, HDL-c and FBGiin the studied groups

\begin{tabular}{|c|c|c|c|}
\hline \multirow{2}{*}{ Parameters \& Correlation } & \multicolumn{2}{|c|}{ FCN2 } \\
\cline { 2 - 4 } & Pearson Correlation & Patient & Control \\
\cline { 2 - 4 } & Sig. (2-tailed) & 0.233 & -0.14 \\
\hline \multirow{3}{*}{ WBC } & Pearson Correlation & 0.114 & 0.55 \\
\cline { 2 - 4 } & Sig. (2-tailed) & 0.549 & -0.21 \\
\hline \multirow{3}{*}{ Plat } & Pearson Correlation & $-0.386^{*}$ & -0.28 \\
\cline { 2 - 4 } & Sig. (2-tailed) & 0.035 & 0.23 \\
\hline \multirow{3}{*}{ Chol } & Pearson Correlation & 0.074 & 0.08 \\
\cline { 2 - 4 } & Sig. (2-tailed) & 0.699 & 0.74 \\
\hline \multirow{2}{*}{ T G } & Pearson Correlation & $-0.457^{*}$ & $-0.581^{*}$ \\
\cline { 2 - 4 } & Sig. (2-tailed) & 0.011 & 0.01 \\
\hline \multirow{2}{*}{ LDL-c } & Pearson Correlation & 0.225 & 0.01 \\
\cline { 2 - 4 } & Sig. (2-tailed) & 0.232 & 0.98 \\
\hline \multirow{2}{*}{ HDL-c } & Pearson Correlation & -0.333 & -0.32 \\
\cline { 2 - 4 } & Sig. (2-tailed) & 0.072 & 0.17 \\
\hline \multirow{2}{*}{ FBG } & Pearson Correlation & 0.201 & 0.20 \\
\cline { 2 - 4 } & Sig. (2-tailed) & 0.287 & 0.39 \\
\hline
\end{tabular}

\section{Discussion}

Hepatitis $\mathbf{C}$ virus (HCV) infects $\mathbf{1 7 0}$ million people worldwide and approximately $\mathbf{8 0 \%}$ of infected individuals develop chronic hepatitis with a risk of progression to cirrhosis and hepatocellular carcinoma ${ }^{[1]}$. HCV infection can cause acute hepatitis $\mathbf{C}$; following acute infection, $50-80 \%$ of patients develop chronic hepatitis C. Chronic HCV infection triggers a chronic inflammatory disease process, which might lead to liver fibrosis, cirrhosis, hepatocellular carcinoma and death. The progression through these stages is a function of time since infection and age of initial infection $^{[12]}$.

HCV virions are 45-65 $\mathrm{nm}$ in diameter and are enveloped in a lipid bilayer in which two envelope glycoproteins (E1 and E2) are anchored. The envelope surrounds the nonicosahedral nucleocapsid, which is composed of multiple copies of the small basic HCV core protein and contains the positive-strand RNA genome of approximately $9.6 \mathbf{~ k b}$, with an open reading frame encoding a single polyprotein of approximately 3,000 amino acids. The structural proteins (core, E1 and E2) are encoded by the amino-terminal part of the open reading frame, whereas the remaining portion codes for the non-structural proteins (p7, NS2, NS3, NS4A, NS4B, NS5A and NS5B) ${ }^{[13]} \mathbf{H C V}$ virions are associated with host low-density lipoproteins (LDLs) and very-low-density lipoproteins (VLDLs), forming what are known as lipoviroparticles. The lipoviroparticles also contain apolipoprotein B(APOB) and other exchangeable apolipoproteins, such as APOC and APOE $^{[14]}$.Complement lectins in human serum are important innate immune molecules. Mannan-binding lectin (MBL) and ficolin are two types of complement lectins that can recognize the surface carbohydrate molecules of microorganisms and subsequently activate the lectin-complement system, which plays a pivotal role ininnate immunity ${ }^{[15,16]}$. Ficolin-2 was first cloned and described as a type of lectin (carbohydrate-binding proteins) with a structure and function similar to C1q, MBL and lung surfactant proteins A and D (SP-A and SP-D) ${ }^{[3]}$. Itpossesses a semiopen structure intermediate between the compact assembly of C1q and the wide open arrangement of MBL which has little interaction between the lectin domains and a buried surface $8 \%$ the size of that of $\mathbf{C 1 q}^{[10]}$. Ficolin-2 is produced mainly by the liver and able to recognize conserved pathogen associated molecular patterns on the 
surface of invading pathogens and initiate the innate immune response ${ }^{[4]}$. Itappears to be a major pattern recognition molecule in human plasma ${ }^{[9]}$.It was found that ficolin-2 had specificity for the HCV envelope glycoproteins $\mathbf{E 1}$ and $\mathbf{E 2}$, resulting in activation of the complement cascade in vitro. However, still there is much debate about its relation to the degree of liver inflammation ${ }^{[10]}$

The current study was planned to evaluate the relationship between ficolin-2 and degree of liver affection in chronic hepatitis $\mathbf{C}$ virus infection.

In the current study the obtained results showed that the mean serum of FCN2 in patient group was $154.39 \pm 48.0$ and in control group it was $66.58 \pm 8.37$. From these results it was noted that FCN2 is significantly increased in both sexes (male and females) of cases group with chronic HCV compared with control group $(\mathrm{P}<0.05$, table 1$)$. More specifically, this study revealed that FCN2 ispositively correlates with elevated ALT values in patients with chronic hepatitis $\mathrm{C}(\mathrm{p}<$ 0.05 table 2).This result is in agreement with that reported by Tarr and McKeating ${ }^{[17]}$ where they revealed that serumficolin-2 concentrations correlated positively with ALT levels in chronic hepatitis C patients with abnormal ALT values $(\mathrm{R}=$ $0.42, \mathrm{P}<0.05$ ), but did not correlate to ALT values in chronic hepatitis $\mathrm{C}$ patients with normal ALT values when liver enzyme consumed. In our study all patient were with abnormal ALT values, and patient with decompensated liver failure were excluded from our study.

The present result also revealed that there wassignificant positive correlation between FCN2 levels and PCR-HCV, Fibro-Scan and $\mathrm{U} / \mathrm{S}$ changes in cases group. This is in agreement with that reported by Zhou $\boldsymbol{e t}$ $\boldsymbol{a l} .{ }^{[18]}$ where they studied 49 patients with chronic hepatitis $\mathrm{C}$ were obtained from Beijing 302 Hospital and Wuhan Medical Treatment Center from 2008 to 2010and they found that ficolin-2 concentrations in chronic hepatitis C patients with elevated ALT values were positively correlated with HCV RNA levels $(\mathrm{R}=0.46, \mathrm{P}<0.05)$ when HCV RNA levels were less than 107 copies $/ \mathrm{ml}$, but not with HCV RNA levels when they were greater than 107 copies $/ \mathrm{ml}(\mathrm{R}=-0.94, \mathrm{P}>0.05)$.
A study described the association of MBL with viral hepatitis, and severity of fibrosis in HCV-infected patients was associated with increased activity of MBL/ MBL-associated serine protease 1 (MASP-1) complex ${ }^{[19]}$. The current study showed that ficolin-2 concentrations positively correlated with the degree of fibrosis and the active state of HCV infection which detected by fibroscan and UIS as follows: ficolin-2 in patients with $\mathrm{HCV}$ infected liver cirrhosis $(\mathrm{F} 2)>$ in patients with $\mathrm{HCV}$ infected liver cirrhosis $(\mathrm{F} 1)>$ in patient with chronic active hepatitis $\mathrm{C}$ (F0). This is also in agreement with described by Liu $\boldsymbol{e t}$ al. [11] that revealedincreased serum ficolin-2 concentration positively correlates with hepatic inflammation and fibrosis. In the current study, the obtained results showed thatthere was significant positive correlation between serum FCN2 levels and T. Bilirubin, INR changes in cases group, and there is significant negative correlation between FCN2 levels and ALB changes in cases group. These agree with synthetic and secretory functions of the liver ${ }^{[20]}$, as the liver is responsible for synthesis of serum and blood clotting factors $(1,2,5,7,9 \& 10)$. When the liver cell affected there is defect in serum ALB and clotting factors production, so the greater the liver cell affection (inflammation) the lesser serum ALB level and the higher INR level. Also the liver is responsible for conjugation of bilirubin and excretion, so when the liver cell affected serum bilirubin elevated due to defect of conjugation and cholestasis.Also, in the present study there was significant positive correlation between FCN2 levels and ALP changes in patients group. This result in agreement with that described by Banner $\boldsymbol{e t}$ al. ${ }^{[21]}$ since immune response and inflammation play key-roles in the elimination of HCV, the higher ALP levels in patients with sustained virological response (SVR) may possibly reflect a higher degree of inflammation. Elevated levels of ALP are found in bone, bowel and bile duct diseases. Their study did not include patients with bone or bowel diseases, the observed significant difference in pre-treatment ALP between patients with relapse and those with SVR might be caused mainly by differing amounts of ALP from the liver or the bile ducts as the primary source of disease. Bile duct inflammation has been reported in up to $95 \%$ of $\mathrm{HCV}$ patients and was shown to correlate 
with serum ALP.The obtained results in the current study revealed also that, there was significant negative correlation between FCN2 levels and Plat changes in patients group. This is in agreement with that documented by Olariu et al. ${ }^{[22]}$. The goal of their study was to determine the prevalent mechanism of thrombocytopenia in patients with chronic hepatitis $\mathrm{C}$ and the clinical predictors of its severity. 81 patients with chronic hepatitis $\mathrm{C}$ and thrombocytopenia were included. The viral inhibition on the bone marrow (central mechanism) was studied by performing bone marrow biopsy from the iliac crest. The presence of anti-platelet antibodies by ELISA assessed the peripheral mechanism. The clinical predictors included in the analysis were: age, gender, ALT level, liver fibrosis stage and HCV RNA. Thrombocytopenia was significantly associated with ALT values, viral load and stage of fibrosis. As the disease advances, the platelet count decreases. This means that the higher the serum FCN2, ALT and HCV RNA levels and degree of liver fibrosis the lower the platelet count. Thrombocytopenia in patients with chronic hepatitis $\mathrm{C}$ may be the result of several factors: bone marrow inhibition, the decrease of liver thrombopoietin production and an autoimmune mechanism. Clinical variables such as age, gender, severity of liver disease and degree of viremia could influence the severity of platelet reduction $^{[23]}$.

\section{CONCLUSION}

Elevated serum FCN2 level in patients with chronic HCV reflects the degree of liver inflammation and fibrosis. The higher the serum FCN2 levels the higher the degree of liver inflammation and fibrosis.

\section{REFERENCES}

1. EI-Serag H (2012): Epidemiology of viral hepatitis and hepatocellular carcinoma. Gastroenterology, 142: 1264-1273.

2. Iwasaki A and Medzhitov R (2010): Regulation of adaptive immunity by the innate immune system. Science, 327: 291- 295.

3. Pan Q, Chen HD, Wang $F$ et al. (2012): L-ficolin binds to glycoproteins $\mathrm{HA}$ and NA and inhibits influenza A virus infection both in vitro and in vivo. J. Innate. Immun., 4:312- 324.
4. Zhang $X$ and Ali $M$ (2008): Ficolins: Structure, function and associateddiseases. Adv. Exp. Med. Biol., 632:105 - 15.

5. Matsushita $M$ (2007): The ficolin family: An overview. In collagenrelated lectins in innate immunity, D. Kilpatrick, Research Signpost. pp 17 31.

6. Hummelshoj T, Fog L, Madsen $\mathrm{H}$ et al. (2008): Comparative study of the human ficolins reveals unique features of Ficolin-3 (Hakata antigen).MolecularImmunology, 45(6): 1623-1632.

7. Keshi T, Sakomoto and T Kawai et al. (2006): Identificationand characterization of novel human collectin CL-K1. Microbiology and Immunology, 50: 1001-1013.

8. Hansen S, Selman L, Palaniyar $\mathrm{N}$ et al. (2010): Collectin 11 (CL- 11, CL$\mathrm{K} 1$ ) is a MASP-1/3-associated plasma collectin with microbial-binding activity. Journal of Immunology, 185(10): 6096-6104.

9. Ma M, Cho M, Zhao N et al. (2004): Human mannose binding lectin and Lficolin function as specific pattern recognition proteins in the lectin activation pathway of complement. The Journal of Biological Chemistry, 279(24): 25307-25312.

10. Garlatti N, Belloy L, Martin A et al. (2007): Structural insights into the innate immune recognition specificities of L-and H-ficolins. EMBO Journal, 26(2): 623-633.

11. Liu J, Ali Y, Shi Y et al. (2009): Specifically binding of L-ficolin to Nglycans of $\mathrm{HCV}$ envelope glycoproteins E1 and E2 leads to complement activation.Cellular and Molecular Immunology, 6(4): 235-244.

12. Stanaway J, Flaxman A, Naghavi $M$ et al. (2016): The global burden of viral hepatitis from 1990 to 2013: findings from the Global Burden of Disease Study 2013. Lancet., 388(10049):10811088.

13. Penin F, Dubuisson J, Rey F et al. (2004): Structural biology of hepatitis C virus. Hepatology, 39: 5-19.

14. André P, Komurian-Pradel F, Deforges $\mathrm{S}$ et al. 
(2002): Characterization of low- and very-low-density hepatitis $\mathrm{C}$ virus RNA-containing particles. J Virol., 76(14):6919-6928.

15. Fujita T, Matsushita and Endo $Y$ (2004): The lectin-complement pathway: its role in innate immunity and evolution. Immunol Rev., 198: 185-202.

16. Garlatti V, Martin M, Lacroix E et al. (2010): Structural insights into the recognition properties of human ficolins. J. Biol. Chem., 285(9):6612622.

17. Tarr A and McKeating $J$ (2014): The past, present and future of neutralizing antibodies for hepatitis $\mathrm{C}$ virus. Antiviral Res., 105: 100-111.

18. Zhau $Y$, Ren $Y$ and Zhang $X$ et al. (2014): Ficolin-2 inhibits hepatitis $C$ virus infection, whereas apolipoprotein E3 mediates viral immune escape. J. of Immunol., 193:783-796.
19. Esmat S, Omran D, Sleem GA et al. (2012): Serum mannan-binding lectin in Egyptian patients with chronic hepatitis C: its relation to disease progression and response to treatment. Hepat. Mon.., 12: 259-264.

20. Guyton AC and Hall JE (2006): Textbook of medical physiology. $11^{\text {th }}$ edi, Saunders Philadelphia, Pennsylvania. PP 1116.

21. Banner BF, Allan C, Smith L et al. (1996): Effect of interferon therapy on bile duct inflammation in hepatitis $\mathrm{C}$. Virchows. Arch., 428:253-259.

22. Olariu M, Olariu $C$ and Olteanu D (2010): Thrombocytopenia in chronic hepatitis C. J. Gastrointestin. Liver Dis., 19(4):381-385.

23. Afdhal N, McHutchison J, Brown $R$ et al. (2008): Thrombocytopenia associated with chronic liver disease. J. Hepatol., 48(6):1000-1007. 